Original Article

\title{
Clinical Outcome of Cortical Venous Thrombosis in Stroke Patients at a Tertiary Care Hospital of Southern Punjab
}

\author{
Sohaib Hassan ${ }^{1}$, Ashraf Mahmood ${ }^{2}$, Ahsan Numan ${ }^{3}$, Asif Mughal ${ }^{4}$, Samra Majeed $^{5}$ \\ ${ }^{1}$ Department of Neurology, Nishtar Hospital Multan, Pakistan. ${ }^{2}$ Neurosurgery, Holy Family \\ Hospital/Rawalpindi Medical University, Rawalpindi, Pakistan. ${ }^{3}$ Department of Neurology, King Edward \\ Medical University, Lahore Pakistan. ${ }^{4}$ Ibne - Sina Hospital Multan, Pakistan. ${ }^{5}$ Department of \\ Neurosurgery, Services Hospital, Lahore - Pakistan.
}

\section{ABSTRACT}

Objective: This study was determined to find out the clinical Outcome of Cortical Venous Thrombosis (CVT) in Stroke patients at a Tertiary Care Hospital of Southern Punjab.

Material \& Methods: A total of 100 patients with cortical venous thrombosis were included in this descriptive case series study, which was conducted at Department of Neurology, Nishtar Hospital Multan. Outcome of patients in terms of partial recovery or complete recovery, any recurrence, any complication, indication for Surgery and any disability in terms of focal deficit, prolonged hospital stay and Mortality was followed.

Results: Our study included a total of 100 patients with cortical venous thrombosis (CVT), 35 (35\%) were male and 65 (65\%) were female patients with their mean age was $37.69 \pm 16.52$ years, ranging from $20-83$ years (51.37 \pm 17.44 in males versus $30.32 \pm 10.15$ years for females). Headache was noted in $80 \%$, focal deficit in $57 \%$, nerve palsy in $30 \%$, coma in $22 \%$ and disability was noted in $35 \%$. Partial recovery was noted in $65 \%$, whereas complete recovery was noted in $35 \%$ while, complications were noted in 12 (12\%) of these patients with CVT.

Conclusion: Cortical venous thrombosis was more prevalent in females in their younger age groups and it was associated with poor prognosis as high frequency of partial recovery was noted in our study.

Keywords: Cortical venous thrombosis, Stroke, headache, recovery, outcome.

Corresponding Author: Sohaib Hassan

Department of Neurology, NMU Multan

Email: hassan.sohaib@yahoo.com

Date of Submission: 15-10-2020

Date of Revision: 21-11-2020

Date of Online Publishing: 25-12-2020

Date of Print: 30-12-2020

DOI: 10.36552/pjns.v24i4.493

\section{INTRODUCTION}

Stroke is a significant cause of mortalities, disabilities and is associated with more than 5 million deaths annually. ${ }^{1,2}$ of these deaths, estimated $66 \%$ of these occur in poor and middle income countries like Pakistan and hence has significant impact on the health economy of these countries due to loss in the productivity of adult 
young population. ${ }^{3}$ It has also been observed that majority of stroke patients in these countries are younger than those from developed countries. World Health Organization (WHO) has estimated that stroke will be the second cause of death in this decade along with cardiovascular diseases in developing countries exhibiting 2 major subtypes; ischemic and hemorrhagic $c^{4,5}$ having different therapeutic techniques emphasizing towards role of diagnostic tools for optimal management of stroke patients. Thrombolytic or anti-platelet therapy is employed in ischemic stroke patients hemostatic therapy is required for the treatment of hemorrhagic stroke ${ }^{6,7}$ and these therapies should, ideally, be started immediately after onset of stroke symptoms to improve outcomes and prognosis. $^{8}$ In addition, stroke patients in underdeveloped countries are 10 years younger than their western counterparts and hence the burden of sustained disability in survivors is greater. ${ }^{9,10}$ Ischemic Stroke accounts for $60-90 \%$ percent of all stroke cases in Pakistan, which occurs due to obstruction of certain blood vessels that supply blood to brain. ${ }^{11}$

An ischemic stroke is of two types, that is, the arterial and venous variety commonly known as cortical venous Thrombosis. The available data suggestedthat cortical venous thrombosis (CVT) is uncommon. An annual incidence of CVT has been reported to be ranging from 0.2 to 1.6 approximately per 100, 000 individuals, being more prevalent in women. This higher proportion imbalance and burden of cortical venous Thrombosis (CVT) in females can be described in terms of pregnancy, use of oral contraceptive drugs and puerperium. ${ }^{12}$ Sassi et al ${ }^{13}$ from Tunisia has reported $6.6 \%$ mortality in CVT and $87.5 \%$ had a good outcome while another study from Oman by $\mathrm{Al}$ - Hashmi et $\mathrm{al}^{14}$ has documented $68.5 \%$ complete recovery, $29.6 \%$ partial recovery and mortality rate was $1.9 \%$.

Upon comprehensive research, it was revealed that there is scarcity of local data on this topic to generate evidence based strategies in our population. The current study aimed to generate useful baseline data based on our local population to ascertain the current magnitude of the problem.This will help to enhance prognosis and clinical outcome of these patients to reduce disease related morbidity and mortality.

\section{MATERIAL \& METHODS}

\section{Sample Size \& Technique}

A total of 100 newly diagnosed patients with cortical venous thrombosis were included in this descriptive case series study, which was conducted at Department of Neurology, Nishtar Hospital Multan from $1^{\text {st }}$ January 2020 to 30 September 2020. The sample size was calculated with WHO sample size calculator for single proportion using mortality $(p)=6.6 \% .^{13}$ The Confidence interval was $95 \%$ and margin of error was 5 . The calculated sample size was 95 which was rounded to 100 patients.

\section{Inclusion Criteria}

100 cases of Fire episode of cortical venous infarct were included.

\section{Exclusion Criteria}

Recurrent cases of cortical venous sinus thrombosis, patients with sepsis \& metabolic abnormalities, patients with co morbidities like chronic renal failure, chronic liver disease and tumors were excluded from our study.

\section{Data Collection}

Prior Permission from Institutional ethical review committee was taken. Informed and written consent were taken and each Patient was evaluated as per written questionnaire.The demographic data including age, sex, residential address, marital Status, educational status \& family income was obtained. Clinical data 
including medical history, family history, history of oral Contraceptive use, presence of risk factors like Pregnancy, hyper-homocystinemia, infection, dehydration, presence of headache, seizure, any focal deficit and duration of Symptoms were obtained. Laboratory data in particular hypercoagulable states like Protein C\&S deficiency, D-Dimers, PT, APTT, Antineutrophil Antibodies, Antiphospholipid Antibodies and cerebrospinal fluid (CSF) findings and involvement of venous sinuses on neuroimaging was obtained and evaluated.

Outcome of patients in terms of partial recovery or complete recovery, any recurrence, any complication, indication for Surgery and any disability in terms of focal deficit and prolonged hospital stay and mortality was followed.

\section{Data Analysis}

All data was entered and analyzed using SPSS v23.0. Frequencies and percentages were described for all of the following categorical variables. Effect modifiers such as gender and marital status was arranged by stratification. There was no bias due to randomization.The main outcome variables were as follows: outcome of treatment (partial recovery, complete recovery or expired), duration of stay in hospital, presence of any recurrence and Presence of any Disability. The dependent variables are as follows: socioeconomic class, pregnancy/ puerperium, presence of seizure and presence of coma.

Post-stratification chi-squared test was applied to assess any relationship between the frequency of different risk
Table 1: Stratification of the outcome with respect to gender.

\begin{tabular}{|c|c|c|c|c|}
\hline \multirow{2}{*}{\multicolumn{2}{|c|}{ Parameter }} & \multicolumn{2}{|c|}{ Outcome } & \multirow{2}{*}{$\begin{array}{c}P \text { - } \\
\text { value }\end{array}$} \\
\hline & & Partial & Complete & \\
\hline \multirow{2}{*}{ Gender } & Male $(n=35)$ & 19 & 16 & \multirow{2}{*}{0.125} \\
\hline & Female $(n=65)$ & 46 & 19 & \\
\hline
\end{tabular}

Table 2: Stratification of the outcome with respect to the residential status.

\begin{tabular}{|c|c|c|c|c|}
\hline \multirow{2}{*}{\multicolumn{2}{|c|}{ Parameter }} & \multicolumn{2}{|c|}{ Outcome } & \multirow{2}{*}{$\begin{array}{c}P \text { - } \\
\text { value }\end{array}$} \\
\hline & & Partial & Complete & \\
\hline \multirow{2}{*}{$\begin{array}{l}\text { Residential } \\
\text { status }\end{array}$} & Rural $(n=53)$ & 35 & 18 & \multirow{2}{*}{0.837} \\
\hline & Urban $(n=47)$ & 30 & 17 & \\
\hline
\end{tabular}

Table 3: Stratification of the outcome with respect to the socioeconomic status.

\begin{tabular}{|c|c|c|c|c|}
\hline \multirow{2}{*}{\multicolumn{2}{|c|}{ Parameter }} & \multicolumn{2}{|c|}{ Outcome } & \multirow{2}{*}{$\begin{array}{c}P \text { - } \\
\text { value }\end{array}$} \\
\hline & & Partial & Complete & \\
\hline \multirow{2}{*}{$\begin{array}{l}\text { Socioeconomic } \\
\text { status }\end{array}$} & Poor $(n=60)$ & 39 & 21 & \multirow[b]{2}{*}{0.999} \\
\hline & $\begin{array}{l}\text { Middle Income } \\
(\mathrm{n}=40)\end{array}$ & 26 & 14 & \\
\hline
\end{tabular}

Table 4: Stratification of the outcome with respect to marital status.

\begin{tabular}{|c|c|c|c|c|}
\hline \multirow{2}{*}{\multicolumn{2}{|c|}{ Parameter }} & \multicolumn{2}{|c|}{ Outcome } & \multirow[b]{2}{*}{ P - value } \\
\hline & & \multirow{2}{*}{$\begin{array}{c}\begin{array}{c}\text { Partial } \\
\text { Recovery } \\
(\mathbf{n}=\mathbf{6 5})\end{array} \\
62\end{array}$} & \multirow{2}{*}{$\begin{array}{c}\text { Complete } \\
\text { Recovery } \\
(\mathbf{n}=\mathbf{3 5}) \\
32\end{array}$} & \\
\hline \multirow{2}{*}{$\begin{array}{l}\text { Marital } \\
\text { status }\end{array}$} & Married $(n=94)$ & & & \multirow{2}{*}{0.420} \\
\hline & Unmarried $(\mathrm{n}=06)$ & 03 & 03 & \\
\hline
\end{tabular}

Table 5: Stratification of the outcome with respect to literacy.

\begin{tabular}{|c|c|c|c|c|}
\hline \multirow{2}{*}{\multicolumn{2}{|c|}{ Parameter }} & \multicolumn{2}{|c|}{ Outcome } & \multirow[b]{2}{*}{ P - value } \\
\hline & & Partial & Complete & \\
\hline \multirow{2}{*}{ Literacy } & Illiterate $(n=57)$ & 42 & 15 & \multirow{2}{*}{0.056} \\
\hline & Literate $(n=43)$ & 23 & 20 & \\
\hline
\end{tabular}


factors and the outcome variables $p$ value less than 0.05 as a level of significance.

\section{RESULTS}

Our study included a total of 100 newly diagnosed patients with cortical venous thrombosis (CVT).

\section{Age and Gender Distribution}

35 (35\%) were male and 65 (65\%) were female patients with their mean age was $37.69 \pm 16.52$ years, ranging from $20-$ 83 years $(51.37 \pm 17.44$ in males versus $30.32 \pm 10.15$ years for females)as shown in Table 1.

\section{Socioeconomic Status}

Thirty five (35\%) were from rural areas as shown in Table 2. $60 \%$ were poor and $40 \%$ were middle income as shown in Table 3.

\section{Marital Status and Literacy}

Ninety four (94\%) were married as shown in Table 4. 57\% were illiterate as shown in Table 5.

\section{Clinical Features}

$26 \%$ had positive family history of stroke as shown in Table $6.20 \%$ were in pro thrombotic condition as shown in Table 7. Use of oral contraceptive drugs was noted in 29\% as shown in Table 8 and dehydration in 22\% in Table 9.

Headache was noted in $80 \%$ as shown in Table 10. Focal deficit in 57\% as shown in Table 11. Nerve palsy in $30 \%$ as shown in Table 12. Coma in $22 \%$ as shown in Table 13 and disability
Table 6: Stratification of the outcome with respect to family history.

\begin{tabular}{|c|c|c|c|c|}
\hline \multirow{2}{*}{\multicolumn{2}{|c|}{ Parameter }} & \multicolumn{2}{|c|}{ Outcome } & \multirow[b]{2}{*}{$P$ - value } \\
\hline & & $\begin{array}{c}\text { Partial } \\
\text { Recovery } \\
(\mathrm{n}=65)\end{array}$ & $\begin{array}{c}\text { Complete } \\
\text { Recovery } \\
(\mathrm{n}=35)\end{array}$ & \\
\hline \multirow{2}{*}{ Family History } & Yes $(n=26)$ & 17 & 09 & \multirow{2}{*}{0.999} \\
\hline & No $(n=74)$ & 48 & 26 & \\
\hline
\end{tabular}

Table 7: Stratification of the outcome with respect to Prothrombotic condition.

\begin{tabular}{|l|l|c|c|c|}
\hline \multirow{2}{*}{ Parameter } & \multicolumn{2}{|c|}{ Outcome } & \multirow{2}{*}{} \\
\cline { 3 - 4 } & $\begin{array}{c}\text { Partial } \\
\text { Recovery } \\
(\mathbf{n}=\mathbf{6 5})\end{array}$ & $\begin{array}{c}\text { Complete } \\
\text { Recovery } \\
(\mathbf{n}=\mathbf{3 5})\end{array}$ & \\
\hline $\begin{array}{l}\text { Prothrombotic } \\
\text { condition }\end{array}$ & Yes $(\mathrm{n}=20)$ & 13 & 07 & \multirow{2}{*}{0.999} \\
\cline { 2 - 4 } & No $(\mathrm{n}=80)$ & 52 & 28 & \\
\hline
\end{tabular}

Table 8: Stratification of the outcome with respect to oral contraceptive.

\begin{tabular}{|l|l|l|l|l|}
\hline \multicolumn{2}{|c|}{} & \multicolumn{2}{|l|}{ Outcome } & \multirow{2}{*}{ Parameter } \\
\cline { 3 - 4 } & $\begin{array}{l}\text { Partial } \\
\text { Recovery } \\
(\mathbf{n}=\mathbf{6 5})\end{array}$ & $\begin{array}{l}\text { Complete } \\
\text { Recovery } \\
(\mathbf{n}=\mathbf{3 5})\end{array}$ & \\
\hline \multirow{2}{*}{$\begin{array}{l}\text { Oral } \\
\text { contraceptive }\end{array}$} & Yes $(n=29)$ & 22 & 07 & \multirow{2}{*}{0.171} \\
\cline { 2 - 4 } & No $(n=71)$ & 43 & 28 & \\
\hline
\end{tabular}

Table 9: Stratification of the outcome with respect to dehydration.

\begin{tabular}{|l|l|c|c|c|}
\hline \multirow{2}{*}{ Parameter } & \multicolumn{2}{|c|}{ Outcome } & \multirow{2}{*}{} \\
\cline { 3 - 4 } & $\begin{array}{c}\text { Partial } \\
\text { Recovery } \\
(\mathbf{n}=\mathbf{6 5})\end{array}$ & $\begin{array}{c}\text { Complete } \\
\text { Recovery } \\
(\mathbf{n}=\mathbf{3 5})\end{array}$ & \\
\hline \multirow{2}{*}{ Dehydration - value } \\
\cline { 3 - 4 } & Yes $(n=22)$ & 10 & 12 & \multirow{2}{*}{0.042} \\
\cline { 2 - 4 } & No $(n=78)$ & 55 & 23 & \\
\hline
\end{tabular}

Table 10: Stratification of the outcome with respect to presence/absence of headache.

\begin{tabular}{|l|l|c|c|c|}
\hline \multirow{2}{*}{ Parameter } & \multicolumn{2}{|c|}{ Outcome } & \multirow{2}{*}{} \\
\cline { 3 - 4 } & $\begin{array}{c}\text { Partial } \\
\text { Recovery } \\
(\mathbf{n}=\mathbf{6 5})\end{array}$ & $\begin{array}{c}\text { Complete } \\
\text { Recovery } \\
(\mathbf{n}=\mathbf{3 5})\end{array}$ & \\
\hline \multirow{2}{*}{ Headache } & Yes $(\mathrm{n}=80)$ & 51 & 29 & \multirow{2}{*}{0.794} \\
\cline { 2 - 4 } & No $(\mathrm{n}=20)$ & 14 & 06 & \\
\hline
\end{tabular}


was noted in 35\% as shown in Table 15.

\section{Outcome and Recovery}

Partial recovery was noted in 65\%, whereas complete recovery was noted in $35 \%$. Parameters like dehydration $(p=$ $0.042)$, nerve palsy $(p=0.043)$, coma ( $p$ $=0.022)$, complications $(p=0.007)$ and disability $(p=0.001)$ showed $a$ significant association with partial recovery as shown in the Tables 9 and 12-15. While, distribution of outcome has been given in each table 1 to 15 . Complications were noted in 12 (12\%) of these patients with CVT as shown in Table 14.
Table 11: Stratification of the outcome with respect to presence/absence of focal deficit.

\begin{tabular}{|c|c|c|c|c|}
\hline \multirow{2}{*}{\multicolumn{2}{|c|}{ Parameter }} & \multicolumn{2}{|c|}{ Outcome } & \multirow[b]{2}{*}{ P - value } \\
\hline & & Partial & Complete & \\
\hline \multirow{2}{*}{ Focal deficit } & Yes $(n=57)$ & 33 & 24 & \multirow{2}{*}{0.095} \\
\hline & No $(n=43)$ & 32 & 11 & \\
\hline
\end{tabular}

Table 12: Stratification of the outcome with respect to presence/absence of nerve palsy.

\begin{tabular}{|l|l|c|c|c|}
\hline \multirow{2}{*}{ Parameter } & \multicolumn{2}{c|}{ Outcome } & \multirow{2}{*}{} \\
\cline { 3 - 5 } & $\begin{array}{c}\text { Partial } \\
\text { Recovery } \\
(\mathbf{n = 6 5 )}\end{array}$ & $\begin{array}{c}\text { Complete } \\
\text { Recovery } \\
(\mathbf{n}=\mathbf{3 5})\end{array}$ & P - value \\
\hline \multirow{2}{*}{ Nerve palsy } & Yes $(\mathrm{n}=30)$ & 24 & 06 & \multirow{2}{*}{0.043} \\
\cline { 3 - 5 } & No $(\mathrm{n}=70)$ & 41 & 29 & \\
\hline
\end{tabular}

Table 13: Stratification of the outcome with respect to presence/absence of coma.

\begin{tabular}{|c|c|c|c|c|}
\hline \multirow{2}{*}{\multicolumn{2}{|c|}{ Parameter }} & \multicolumn{2}{|c|}{ Outcome } & \multirow[b]{2}{*}{ P - value } \\
\hline & & Partial & Complete & \\
\hline \multirow{2}{*}{ Coma } & Yes $(n=22)$ & 19 & 03 & \multirow{2}{*}{0.022} \\
\hline & No $(n=78)$ & 46 & 32 & \\
\hline
\end{tabular}

Table 14: Stratification of the outcome with respect to complication.

\begin{tabular}{|c|c|c|c|c|}
\hline \multirow{2}{*}{\multicolumn{2}{|c|}{ Parameter }} & \multicolumn{2}{|c|}{ Outcome } & \multirow[b]{2}{*}{ P - value } \\
\hline & & Partial & Complete & \\
\hline \multirow{2}{*}{ Complications } & Yes $(n=12)$ & 12 & 00 & \multirow{2}{*}{0.007} \\
\hline & No $(n=88)$ & 53 & 35 & \\
\hline
\end{tabular}

Table 15: Stratification of the outcome with respect to presence/absence of disability.

\begin{tabular}{|c|c|c|c|c|}
\hline \multirow{2}{*}{\multicolumn{2}{|c|}{ Parameter }} & \multicolumn{2}{|c|}{ Outcome } & \multirow[b]{2}{*}{ P - value } \\
\hline & & Partial & Complete & \\
\hline \multirow{2}{*}{ Disability } & Yes $(n=35)$ & 32 & 03 & \multirow{2}{*}{0.001} \\
\hline & No $(n=65)$ & 33 & 32 & \\
\hline
\end{tabular}




\section{DISCUSSION}

Cortical venous thrombosis (CVT) is regarded as uncommon neurovascular disorder presenting with a high degree of variation in clinical presentation, diverse etiologies $\&$ disease course and may lead to late diagnosis due to less burden of the disease and incongruous presentation with its incidence being reported around 5 million per year. ${ }^{15,16}$ Incidence of CVT is increasing day by day due to advancement of diagnostic modalities (such as CT and MRI) all over the world and new cases are being reported regularly showing upward trends in disease burden. ${ }^{17,18}$ Early diagnosis is crucial for the prognosis of the disease which leads to the early recovery, return to work, physical activities and productivity of the patient. ${ }^{15-18}$ We performed this study in 100 newly diagnosed patients of the CVT to ascertain the outcome of the CVT in these patients.

Our study included a total of 100 newly diagnosed patients with cortical venous thrombosis (CVT), 35 (35\%) were male and 65 (65\%) were female patients. A study conducted by Wasay et al $^{19}$ from Karachi has also reported high female gender preponderance with $60 \%$ female patients. A study conducted in different parts of the world by Khealani et $\mathrm{al}^{20}$ has also reported 53\% CVT patients were females. Devasagayam et $\mathrm{al}^{21}$ also reported $52 \%$ female patients with CVT from Australia, similar to our results. Coutinho et $a^{22}$ from Netherland has also reported $72 \%$ female gender preponderance in CVT patients. Mehndiratta et $\mathrm{al}^{23}$ from India has also reported $66 \%$ CVT female patients' preponderance.

Mean age of our patients was $37.69 \pm 16.52$ years, ranging from 20 - 83 years. A study conducted by Wasay et al ${ }^{19}$ from Karachi has also reported 37 years as the mean age in CVT patients. A study conducted in different parts of the world by Khealani et $\mathrm{al}^{20}$ has also reported $35.76 \pm 13.15$ years as the mean age of the CVT patients showing similar results and also reported that female CVT patients were significantly younger than male patients. Devasagayam et $\mathrm{al}^{21}$ from Australia reported 49 years mean age, which is slightly higher which indicates that CVT is more prevalent in our population in younger ages. Similar to our results, another study conducted by Coutinho et $\mathrm{al}^{22}$ from Netherland has also reported 41 years as median age. Mehndiratta et $\mathrm{al}^{23}$ from India has reported 41.5 years as a mean age among male CVT patients compared with 27.75 years as a mean age for female CVT patients, showing similar trends of disease burden in young females as that of our results.

Thirty five (35\%) were from rural areas, $60 \%$ were poor and $40 \%$ were middle income. Ninety four (94\%) were married, $57 \%$ were illiterate, $26 \%$ had positive family history of stroke, $20 \%$ were in prothrombin condition, use of oral contraceptive drugs was noted in $29 \%$ and dehydration in $22 \%$. A study conducted by Wasay et al ${ }^{19}$ from Karachi has also reported similar results. Devasagayam et $\mathrm{al}^{21}$ from Australia reported $31 \%$ use of oral contraceptive drugs in CVT patients, similar to our findings. Coutinho et $\mathrm{al}^{22}$ from Netherland has also reported $52 \%$ use of oral contraceptive drugs.

Headache was noted in $80 \%$, focal deficit in $57 \%$, nerve palsy in $30 \%$, coma in $22 \%$ and disability was noted in $35 \%$. A study conducted by Wasay et al $^{19}$ from Karachi has also reported $68 \%$ headache, coma in $19 \%$ and $23 \%$ neurological deficit, similar to our results. A study conducted in different parts of the world by Khealani et $\mathrm{al}^{20}$ has also reported $81 \%$ headache, $45 \%$ focal deficit and $37 \%$ coma.

Partial recovery was noted in $65 \%$, whereas complete recovery was noted in $35 \%$ and complications were noted in 12 (12\%) of these patients with CVT. A study conducted in different parts of the world by Khealani et $\mathrm{al}^{20}$ has reported $6 \%$ mortality and $40 \%$ partial recovery while in our study there was no mortality while $65 \%$ CVT patients had partial recovery. Devasagayam et $\mathrm{al}^{21}$ 
from Australia reported $12 \%$ mortality, however, there was no mortality in our study.

In our study, various underlying factors such as dehydration $(p=0.042)$, nerve palsy ( $p=$ 0.043 ), coma ( $p=0.022)$, complications ( $p=$ $0.007)$ and disability $(p=0.001)$ showed $a$ significant association with partial recovery. Khealani et $\mathrm{al}^{20}$ has reported coma and functional status to be predictors of poor outcomes on univariate analysis, similar to our results while Khealani et $\mathrm{al}^{20}$ also reported coma was an independent predictor of mortality in these patients. However there was no mortality in our study cases. Similar results have been reported by Kalita et $\mathrm{l}^{3}$ from India.

\section{CONCLUSION}

Cortical venous thrombosis was more prevalent in females in their younger age groups and it was associated with poor prognosis as high frequency of partial recovery was noted in our study. Partial recovery was significantly associated with literacy, dehydration, nerve palsy, coma, complications and disability.

\section{Limitation}

This study conducted on a limited number of sample size and thus further studies are required for evaluation.

\section{REFERENCES}

1. Maali L, Khan S, Qeadan F, Ismail M, Ramaswamy D, Hedna VS. Cerebral venous thrombosis: continental disparities. Neurol Sci. 2017; 38 (11): 1963-1968. Doi: 10.1007/s10072-017-3082-7.

2. Goyal G, Charan A, Singh R. Clinical Presentation, Neuroimaging Findings, and Predictors of Brain Parenchymal Lesions in Cerebral Vein and Dural Sinus Thrombosis: A Retrospective Study. Ann Indian Acad Neurol. 2018; 21 (3): 203-208.

Doi: 10.4103/aian.AIAN_470_17.

3. Kalita J, Singh VK, Jain N, Misra UK, Kumar S. Cerebral Venous Sinus Thrombosis Score and its
Correlation with Clinical and MRI Findings. J Stroke Cerebrovasc Dis. 2019; 28 (11): 104324.

Doi: 10.1016/j.jstrokecerebrovasdis.2019.104324.

4. Wang Y, Meng R, Duan J, Liu G, Chen J, Li S, Ji X. Nephrotic Syndrome May Be One of the Important Etiologies of Cerebral Venous Sinus Thrombosis. J Stroke Cerebrovasc Dis. 2016; 25 (10): 2415-22. Doi: 10.1016/j.jstrokecerebrovasdis.2016.06.013.

5. Gunes HN, Cokal BG, Guler SK, Yoldas TK, Malkan UY, Demircan CS, Yon MI, Yoldas Z, Gunes G, Haznedaroglu IC. Clinical associations, biological risk factors and outcomes of cerebral venous sinus thrombosis. J Int Med Res. 2016; 44 (6): 1454-1461. Doi: $10.1177 / 0300060516664807$.

6. Lee DJ, Ahmadpour A, Binyamin T, Dahlin BC, Shahlaie K, Waldau B. Management and outcome of spontaneous cerebral venous sinus thrombosis in a 5-year consecutive single-institution cohort. J Neurointerv Surg. 2017; 9 (1): 34-38.

Doi: 10.1136/neurintsurg-2015-012237.

7. Jankowitz BT, Bodily LM, Jumaa M, Syed ZF, Jovin TG. Manual aspiration thrombectomy for cerebral venous sinus thrombosis. J Neurointerv Surg. 2013; 5 (6): 534-8. Doi: 10.1136/neurintsurg-2012010476.

8. Adachi $H$, Mineharu $Y$, Ishikawa $T$, Imamura $H$, Yamamoto $S$, Todo K, Yamagami $H$, Sakai $N$. Stenting for acute cerebral venous sinus thrombosis in the superior sagittal sinus. Interv Neuroradiol. 2015; 21 (6): 719-23.

Doi: 10.1177/1591019915609120.

9. Zhang $S$, Hu Y, Li Z, Huang $D$, Zhang $M$, Wang $C$, Wang Z. Endovascular treatment for hemorrhagic cerebral venous sinus thrombosis: experience with 9 cases for 3 years. Am J Transl Res. 2018; 10 (6): 1611-1619.

10. Wang $Y$, Zhao C, Huang D, Sun B, Wang Z. Stent retriever thrombectomy combined with long-term local thrombolysis for severe hemorrhagic cerebral venous sinus thrombosis. Exp Ther Med. 2020; 20 (5): 66. Doi: 10.3892/etm.2020.9194.

11. Ilyas $A$, Chen CJ, Raper DM, Ding $D$, Buell $T$, Mastorakos P, Liu KC. Endovascular mechanical thrombectomy for cerebral venous sinus thrombosis: a systematic review. J Neurointerv Surg. 2017; 9 (11): 1086-1092.

12. Cabral de Andrade G, Lesczynsky A, Clímaco VM, Pereira ER, Marcelino PO, Franco A, De Almeida 
DF. Cerebral venous sinuses thrombosis in both transverse sinus and torcula: Multistep endovascular treatment and stenting. Interv Neuroradiol. 2017; 23 (1): 84-89.

Doi: $10.1177 / 1591019916674917$.

13. Sassi SB, Touati N, Baccouche $H$, Drissi C, Romdhane NB, Hentati F. Cerebral Venous Thrombosis: A Tunisian Monocenter Study on 160 Patients. Clin Appl Thromb Hemost. 2017; 23 (8): 1005-1009. Doi: 10.1177/1076029616665168.

14. Al Hashmi K, Al Wahaibi K, Al-Khabori M, Al Lamki S. Characteristics and Outcomes of Patients with Cerebral Venous Sinus Thrombosis. Oman Med J. 2019; 34 (5): 434-437. Doi: 10.5001/omj.2019.79.

15. Bushnaq SA, Qeadan F, Thacker T, Abbas M, Carlson AP. High-Risk Features of Delayed Clinical Progression in Cerebral Venous Thrombosis: A Proposed Prediction Score for Early Intervention. Interv Neurol. 2018; 7 (6): 297-307.

Doi10.1159/000487960

16. Siddiqui FM, Weber MW, Dandapat S, Scaife $S$, Buhnerkempe $M$, Ortega-Gutierrez S, Aksan N, Elias A, Coutinho JM. Endovascular Thrombolysis or Thrombectomy for Cerebral Venous Thrombosis: Study of Nationwide Inpatient Sample 2004-2014. J Stroke Cerebrovasc Dis. 2019; 28 (6): 1440-47.

Doi: 10.1016/j.jstrokecerebrovasdis.2019.03.025.

17. Nasr DM, Brinjikji W, Cloft HJ, Saposnik G, Rabinstein AA. Mortality in cerebral venous thrombosis: results from the national inpatient sample database. Cerebrovasc Dis. 2013; 35 (1): 40-4. Doi: 10.1159/000343653.

18. Korathanakhun P, Sathirapanya P, Geater SL, Petpichetchian W. Predictors of hospital outcome in patients with cerebral venous thrombosis. J Stroke Cerebrovasc Dis. 2014; 23 (10): 2725-2729. Doi: 10.1016/j.jstrokecerebrovasdis.2014.06.020.

19. Wasay M, Kojan S, Dai Al, Bobustuc G, Sheikh Z. Headache in cerebral venous thrombosis: incidence, pattern and location in 200 consecutive patients. J Headache Pain. 2010; 11: 137-39.

20 Khealani BA, Wasay $M$, Saadah $M$, Sultana $E$, Mustafa S, Khan FS, Kamal AK. Cerebral venous thrombosis: a descriptive multicenter study of patients in Pakistan and Middle East. Stroke, 2008; 39(10):2707-11.

Doi: 10.1161/STROKEAHA.107.512814.

21. Devasagayam S, Wyatt B, Leyden J, Kleinig T. Cerebral Venous Sinus Thrombosis Incidence is Higher Than Previously Thought: A Retrospective Population-Based Study. Stroke, 2016; 47 (9): 2180-2.

22. Coutinho JM, Zuurbier SM, Aramideh M, Stam J. The incidence of cerebral venous thrombosis: a cross-sectional study. Stroke, 2012; 43 (12): 33757. Doi: $10.1161 /$ STROKEAHA.112.671453.

23. Mehndiratta M, Garg S, Gurnani M. Cerebral venous thrombosis - clinical presentations. J Pak Med Assoc. 2006; 56 (11): 513-5.

\section{Additional Information}

Disclosures: Authors report no conflict of interest.

Ethical Review Board Approval: The study was conformed to the ethical review board requirements.

Human Subjects: Consent was obtained by all patients/participants in this study.

Conflicts of Interest:

In compliance with the ICMJE uniform disclosure form, all authors declare the following:

Financial Relationships: All authors have declared that they have no financial relationships at present or within the previous three years with any organizations that might have an interest in the submitted work.

Other Relationships: All authors have declared that there are no other relationships or activities that could appear to have influenced the submitted work. 


\section{AUTHORS CONTRIBUTIONS}

\begin{tabular}{|l|l|l|}
\hline Sr.\# & Author's Full Name & Intellectual Contribution to Paper in Terms of: \\
\hline 1. & Sohaib Hassan & $\begin{array}{l}\text { 1. } \text { Study design and methodology \& Data collection and } \\
\text { calculation, Paper writing. }\end{array}$ \\
\hline 2. & Ashraf Mahmood & 2. Paper writing, referencing, data calculations. \\
\hline 3. & Ahsan Numan & 3. Analysis of data and quality insurer. \\
\hline 4. & Asif Mughal Senior & 4. Analysis of data and interpretation of results etc. \\
\hline 5. & Samra Majeed & 5. Literature review and manuscript writing. \\
\hline
\end{tabular}

